\title{
The nature of experience and learning for japanese girls in a highschool basketball club
}

\author{
Richard L. Light \\ University of Canterbury \\ Wataru Yasaki \\ Tokyo University of Science
}

\begin{abstract}
This article draws on a study that inquires into what keeps girls aged 13-16 years in a high school basketball club in Japan with a focus on how the nature of their experience is shaped by socio-cultural and institutional context. The influence of context is of particular importance in small-scale, close-focus studies such as the study drawn on in this article and is emphasized due to the way in which the context is culturally distinct from Western settings. While the findings support those of some other studies on adolescent girls participation in sport they identify the influence of the institutional culture of schools and bukatsudō (clubs). Located within the larger Japanese cultural context on the nature of experience in school basketball and the learning emerging from it to identify the implicit yet powerful influence of the cultural learning that underpins Japanese education.
\end{abstract}

Keywords: basketball club; japanese adolescent girls, learning experiences, ethnography

Résumé: Cet article analyse ce qui maintient engagé des filles âgées de 13-16 ans dans un club de basket-ball à l'école secondaire au Japon en mettant l'accent sur leur expérience en lien avec le contexte socio-cultuel et institutionnel. Cette étude analyse à un grain fin le contexte qui revêt une importance particulière à petite échelle, d'autant plus lorsqu'il diverge considérablement de la culture occidentale. Bien que ces résultats entrent en continuité avec d'autres études sur la participation sportive des jeunes filles, ils montrent l'influence particulière de la culture institutionnelle des écoles et des bukatsudō (clubs). Les apprentissages émergent du contexte avec une influence implicite mais puissante de l'apprentissage culturel qui sous-tend l'éducation japonaise dans le contexte culturel japonais le plus répandu dans le basket-ball scolaire.

Mots-clés : club de basketball, adolescentes japonaises, expériences d'apprentissage, ethnographie 


\section{Introduction}

W

ithin the literature on children's and young people's participation in sport a number of studies have focused on identifying barriers to participation and participants' reasons for dropping out (see, Fraser-Thomas, Coté, \& Deakin, 2008). Others have focused on why children and young people take up sport and remain with it and the factors that facilitate their participation in it (see, Bailey, Cope \& Pearce, 2013; Light, Harvey \& Mermmert, 2013). This article draws on a study that takes this positive approach to focus on what keeps girls aged 13-16 in a Japanese secondary school basketball club and how this is influenced by socio-cultural and institutional context. This study formed part of a larger study focused on what keeps girls aged 13-16 participating in basketball clubs in Australia, Portugal and Japan.

Conducted in a setting that is culturally distinct from Western settings, this study highlights the powerful influence of the institutional culture of schools and school clubs (bukatsudō), located within the larger Japanese cultural context, on experience and the meaning the girls make of being in the school basketball club and their particular team.

\section{Young people and participation in sport}

The most common reasons for children and young people taking up and staying in sport are related to parental influence, self perceptions of physical competence, social acceptance, and enjoyment (Côté \& Hay, 2002; McCarthy \& Jones, 2007). In a meta analysis of studies on sport participation Allender, Cowburn and Foster, (2006) suggest that children are most motivated to participate when they are not forced to compete and expected to win and have the opportunity to play a range of different sports (see also, MacPhail, Gorely \& Kirk, 2003).

Reasons for withdrawing from sport include competition between sport and other interests for time and energy, a lack of fun and excitement, a lack of playing time, poor relationships with coaches, reductions in free-playing time and an over-emphasis on winning (Fraser-Thomas et al., 2008; Weiss and Williams, 2004). This is particularly marked in the early teenage years when, according to the DMSP (Development Model for Sport Participation - Côte \& Hay, 2002) young people move from a sampling phase (6-12 years) to a specializing phase (13-16). It involves a shift from sampling a range of different sports with an emphasis on fun and deliberate (structured) play to specializing in one sport with an emphasis on deliberate practice. This transition from a sampling phase to a specializing phase occurs at a time when young people must also deal with the major change in their lives that is involved in moving from primary to secondary school and the major physical and psychological changes associated with reaching 
puberty (Côté \& Hay, 2002). Drop out from sport among girls peaks at around 13 years of age as they transition from a sampling phase to a specializing phase (Olds, Dollman \& Maher, 2009), which is the reason why this study focuses on girls in the specializing phase.

\section{Girls' participation in sport}

Learning new skills, improving self-esteem and developing social networks are factors that can make sport positive for teenage girls (see, Flintoff \& Scratton, 2003) but Allender et al. (2006) identify concern with body image among teenage girls as their main reason for playing sport. Family and peer support is also important for teenage girls playing sport and particularly when changing schools in their journey from childhood to adulthood due to the threat that this transition poses to their participation in sport (Coakley \& White, 1992).

Tensions between the positive experience of being physically active and concerns about perceptions of their femininity add to the complexity of teenage girls' participation in sport (Allender et al., 2006). The links between women, femininity and sport are far more problematic than the one between men, masculinity and sport because sport remains a dominantly masculinist practice that plays a central role in the reproduction of gender inequality (Connell, 1983).

\section{The social nature of sport for young people}

Sport is essentially a social activity and particularly when practised in community club and school settings (see, Light, 2010). However, with some exceptions, the ways in which the complexity of these sociocultural contexts shapes experience and learning, and how this experience and learning overlaps with other areas of social life has not yet been adequately addressed in the literature on children's and young people's participation in sport. Some of the exceptions highlight the pivotal role that the socio-cultural context of sports clubs as communities plays in young peoples learning and development (Light, 2010; MacPhail, Gorley \& Kirk, 2003) while other studies emphasize the influence of other communities of practice and of larger socio-cultural and institutional contexts across a range of settings (Light \& Nash, 2006; Light, 2008; Wright \& Macdonald, 2010). These studies suggest that the immediate social and cultural context assumes a very important role in influencing participation and development that includes the development of personal identity and a sense of belonging, social learning and a sense of competency (Light, 2010, 2006; MacPhail et al., 2003).

Youth sport clubs are not merely places where young people learn the skills of a sport. They are also social sites that have official and unofficial agendas (Kirk \& MacPhail, 2003). Part of the knowledge of what a sport club is, and the multiple and overlapping practices that make the club a dynamic and living community, means that there are 
always tensions, conflicts and complexities that need to be understood further (Kirk \& MacPhail, 2003). It is not only important to understand the immediate social and cultural context of clubs but also the larger cultural and social settings within which they operate when inquiring into experience and learning (Light, 2016). This means that there is a pressing need for alternatives to large scale quantitative studies that are capable of being sensitive to the contextual, social, economic and cultural factors which influence participation in physical activity (Allender et al., 2006).

\section{Sport and education in Japan}

Since their inception in the late $19^{\text {th }}$ century, institutions of mass education in Japan have formed central mechanisms for the maintenance of social cohesion and the promotion of culturally valued traits such as perseverance, self control, humility, respect for order and developing moral 'character' (Passin, 1980; Rohlen, 1980). Despite profound social and economic change in Japan since the Meiji era (1968-1912) schooling in Japan remains underpinned by the resilient notion of cultural learning as a hidden curriculum (Singleton, 1993). Beyond just developing a skilled workforce, Japanese schools and universities are seen to prepare young people for entry in the "rigorous, hierarchical, and finely tuned organizational environment" of work after school (Miller, 2013) with an overarching emphasis placed upon moral and cultural learning (Rohlen, 1983, 1986). The role the academic curriculum in Japan plays in moral and cultural learning is not so easily identified but the use of sport for cultural learning is far more visible (see, Light, 1999, 2008; McDonald \& Komuku, 2008).

Despite lingering cultural inequality in Japan for girls and women the emphasis placed upon embodied cultural learning is the same for girls as it is for boys (Ikeda, 2010). The cultural learning that Singleton (1993) argues underpins education in Japan has long been seen to be essential for social cohesion in Japan. It is something that is highly valued in corporate Japan (see, Rohlan, 1986) with van Ommen (2015) suggesting it operates as a form of embodied cultural capital that can be exchanged for economic capital in the form of rewarding employment. Females are still significantly disadvantaged in Japan in terms of access to secure employment and with a gap of approximately thirty percent in salaries (Broadbent, 2003; OECD, 2014).

The rigours of schooling in Japan associated with exam hell (jigoku jigoku) are well documented (see, Doyon, 2001) but less is known about the hidden curriculum of cultural learning that underpins education in Japan (Singleton, 1993). Unlike Western countries where students are typically categorized as underachievers or overachievers, cultural imperatives such as persistence, self-sacrifice and effort are seen to be the key to success in the Japanese education system (Rohlen, 1983; 
Singleton, 1993). Singleton suggests that the cultural curriculum operates implicitly as a means of achieving the goal of cultural learning with the deep content of any educational process being seishin (life spirit) and shudan ishiki (group consciousness or belongingness) with studies on sport conducted in Japanese educational settings supporting this contention (see, Light, 1999, 2001; McDonald, 2004). This emphasis on cultural learning extends well beyond schools to include the informal learning that arises from participation in all cultural activities ranging from shodo (the way of calligraphy) to budo (martial arts), sport and corporate training programs for new employees (see, Light, 1999; Rohlen, 1986).

In Japan corporeal experience is central to cultural learning such as in the martial arts where practitioners must constantly overcome challenging tasks that test them physically, emotionally and mentally in the pursuit of selfless perfection (see, Herrigal, 1971; Suzuki, 1959). Sitting upon Eastern monist philosophical traditions, there is a long history of learning through the body and corporeal experience with an emphasis on cultural learning (Yuasa, 1993). As Singleton (1993: p. 12) suggests, "Carefully constructed experience is more powerful than telling or lecturing. One learns from the experience of hardships, conquering difficult tasks, developing perfection in particular skills".

During the post Pacific War rebuild of Japan its education system was modelled on the US system within which sport continued to be seen as a vehicle for learning culturally valued traits, 'character', and culturespecific morality (Passin, 1980). Team sports such as rugby, baseball and basketball were introduced in Japan during the late nineteenth century with their practice, meaning and purpose significantly shaped by dominant Japanese culture developed from the Meiji era (1868-1912) as a period of rapid social and economic change (Light, 1999; Roden, 1980). Leading educators during the Meiji era recognized the value of team sports and the games ideology for the newly formed system of mass schooling as a means of promoting social cohesion (Roden, 1980). Team sports have long since been seen as important elements of Japanese education systems and a means of promoting preferred social development of young people (McDonald \& Komuku, 2008; Abe, Kiyoharam \& Nakajima, 1990; Roden, 1980). With education bureaucrats responsible for sports policy, the sporting space has long been considered educational space (Miller, 2013).

\section{Bukatsudō}

Up until the radical changes made in the structure and practice of football in Japan from 1993 access to, and participation in, sport for adolescents was limited to school based physical education and sports clubs (see, Ichiro, 2004; Light \& Yasaki, 2003). Despite the success of the J. League and the emergence of other community based and 
commercial sports clubs since then, access to sport for most Japanese adolescents is still limited to extra-curricula clubs called bukatsudō. Bukatsudo have a long history of being used to promote order, selfhood, and features of traditional Japanese culture through combining appeal to individual enthusiasm and agency, opportunities for intense and meaningful relationships, and demands for disciplined commitment (Cave, 2004). Learning in bukatsudo follows a model based on observation and activity, which is quite different to the model of the secondary school classroom (Cave, 2004). There are strong parallels between the importance of order, selfhood, and learning in bukatsudo, and in the world of Japanese adults (Cave, 2004).

Miller (2013) suggests that, unlike most Western sports clubs, they do not focus on developing or lauding talented individuals or provide them with the visibility that builds up status through successful performance. Instead, they emphasize students striving to perfect their performance in the fundamental techniques of the sport as part of a process of socializing them into the hierarchical, self-disciplined behaviour required to function in adult society. They form central learning experiences in the cultural curriculum that underpins all learning in and around schools in Japan (Singleton, 1993). In school or university rugby, baseball or basketball teams there is no individual award given such as 'best and fairest' with the emphasis on the team as a whole and the need for the individual to control individual desire for the sake of the team (Light, 2008).

\section{Methodology}

A constructivist grounded theory approach was adopted to provide insight into the social environment and to understand the human action and interaction that shaped learning (Charmaz, 2006; Glaser \& Strauss, 1967; Strauss \& Corbin, 1990).

\section{The site}

The study was conducted in a sixteen-years and under team in a basketball club within a single sex private school in Tokyo that included junior and senior secondary divisions in the one school. This is unusual in Japan as the structure of schooling follows the US model of having separate middle and high schools. The school was well regarded and ranked academically with most girls aspiring to enter higher end universities.

\section{The participants}

In a club of 31 girls there was one team of girls aged 13 to 16 years of age with 10 members. Invitations to take part in the study were sent out to the parents of all thirty-one in the club girls with the questionnaire. Nine parents of girls in the team replied and gave permission for their daughters to take part in the study. Six girls were then chosen at random 
in one team to participate in the interviews with pseudonyms used to safeguard their identity. Ethical approval was gained from the university of the second author. Jyuri and Eriko were thirteen years old, Chika was fourteen years old, Reiko was fifteen years old and both Sachi and Junko were sixteen years old.

\section{Data generation and analysis methods}

Data were generated and analyzed using a constructivist grounded methodology (GTM, Chamaz, 2006). The process began with an initial questionnaire sent to all 31 girls in the school basketball club with 20 responding. The questionnaires were aimed at providing broad background information about the club, the nature of the girls' participation in basketball and their reasons for joining and staying in the club. The data from the questionnaire was analyzed to identify areas to explore in the first round of three semi structured interviews, each of 30 minutes duration and conducted by the second author who is a native speaker. Interview one had questions directed at understanding why the girls joined the club and the nature of their experiences of being in the team and club, which were transcribed verbatim.

With data analysis and generation an ongoing process in GTM we describe some of the steps involved and some of the important tools and strategies used. Once an interview was conducted it was transcribed verbatim as soon as possible. During transcription notes were made in a research diary by the second author on things that he felt we might have needed clarity to provide an overview of the interview and an understanding of the big ideas that we felt seemed to be emerging (Richards, 2010). These were then compared to the interviews (or questionnaire) from the other girls in the study in a constant comparative method that generated emerging themes and questions to be answered in subsequent interviews. Interviews were coded line-by-line (Glaser, 1978) and, following Auerbach and Silverstein's (2003) suggestions, we picked out what we felt was relevant text. Memos were also used to develop themes from which we conceptualized the data into emerging categories (Clarke \& Friese, 2010; Lempert, 2010).

\section{Results}

Three strong themes emerged from the grounded theory process as the big ideas that were developed into three categories used to identify what most contributed to the participants' enjoyment of basketball. They are presented here in order of importance of the contribution they made toward keeping the six girls in the basketball team. They are: (1) the social environment and relationships, (2) satisfaction from commitment and self-sacrifice, (3) having a sense of improvement and learning. 


\section{Social environment and relationships}

Relationships within the team and the importance of being part of it as a collective were central to the girls' enjoyment and the meaning that being in the team held for them. This reflects the importance of friendships and interaction with, and feelings of support from, same sex peers in sport for adolescent girls suggested in the literature (Weiss \& Smith, 2003; Chen \& Light, 2006; Coakley \& White, 1992). For some, friends influenced their decisions to join the club with Reiko and Sachi joining due to the encouragement of friends already playing in the club and Junko joining because basketball was the most popular sport in school meaning that many of her friends were already in the club.

When asked what the best thing was about being in the team, most referred to the good relationships and positive interaction between them. This extended beyond just being friends to caring for others and feeling cared for and valued by all the girls in the team:

The best thing in this team is to have strong friendship. We take care of each other so we have made very good friends in the team. I made a lot of friends through basketball, over twenty friends I think (Interview, Jyuri).

This suggests the importance of social networks for adolescent girls (Flintoff \& Scratton, 2003) and of caring environments for positive experiences of sport (see, Fernandez-Balboa, 2011; Fry \& GanoOverway, 2010). All six girls valued getting support and encouragement from their teammates and felt that they shared a strong, common feeling of belonging and relatedness which is a common finding in research on girls in sport (see, Flintoff \& Scratton, 2003; Sarrazin, Vallerand, Guillet, Pelletier \& Cury, 2002). They emphasized the importance of feeling they were an important part of the team as a well-functioning social unit. This reflects some gender specific characteristics of their experience and some of the cultural learning promoted in bukatsudo in the form of shudan ishiki (group consciousness or belongingness) that underpins education in Japan (Cave, 2004; Singleton, 1993). This learning of group consciousness and commitment to the team and club promotes sensitivity to relationships and commitment to the team as Reiko suggests:

I always relate to my teammates with consideration for them, which is the key to getting on with them very well. I think that (this year) we developed strong friendships and relationship between us all in our team. We also always do something together out of basketball (Interview, Reiko).

The study initially suggested a strong sense of respect for each other in the team but as the grounded theory process progressed and emerging themes were developed evidence of tensions emerged that suggested some contradictions between the team harmony and common sense of 
purpose as an ideal and the reality of tensions between some girls in the team. In bukatsudo there is a strong hierarchical relationship (joge kanke) between seniors (sempai) and juniors (kohai) that provides a strong social structure for behaviour. Typically, first year students must show respect for their seniors and perform menial and demanding tasks to reinforce their low status in the club, working their way up to the senior position of sempai, year by year during which they experience the hierarchical structure of the society and the workplace (see, Light, 1999, 2001, 2008). It is something that figured strongly for one of the senior girls:

I have good relationships with my teammates. I am not sure that we have a strong friendship but I think that we have tried to get on with teammates together based on valuing relationship between older (sempai) and younger (kohai) teammates (Interview, Junko).

This tension seemed to arise from some girls not fitting so well into the strict hierarchical structures typically found in school sports clubs and which can create stress for students (van Ommen, 2015). This was also evident with girls who expressed displeasure with teammates being self-assertive (jiko shuchou) and selfish (wagamama). For example, Junko felt that the junior members of the team were interfering with the harmony of the team that its hierarchical structure (joge kankei) provides: "It is annoying when some girls are self-assertive because it disrupts the harmony ( $w a$ ) of the team".

School sports clubs convey the message of shudan ishiki as part of the hidden curriculum of cultural learning (Singleton, 1993). They develop commitment to the group and learning how to live in a grouporiented society with membership in sports clubs involving learning how to play the game for life cooperatively (Kiefer, 1970). Like Junko, Chika expressed discomfort with players who were too self-assertive because she felt that it disrupted the harmony of the team. She was disappointed that they could not demonstrate the expected self-control required to fit into a harmonious social group:

I think that it is important for us to suppress self-assertion sometimes. Although, at the same time, we may like that, this has to be done so that I get on with my teammates and we develop strong friendships in the team (Interview, Chika).

The study revealed some different perspectives and attitudes within the teams that the participants recognized and tried to work together to minimize the extent to which it created tension and to enhance team harmony $(w a)$. The good relationship between teammates that was apparent early in the study seemed to be superficial at times as the study 
progressed with Junko questionning whether or not they actually did have strong friendships.

In the early stages of the study the emerging category of the importance of relationships within the team seemed very strong but as the GTM process progressed we found contradictions. These suggested the complexity of relationships within the team but did not detract from inter-personal relationships being the most influential factor facilitating participation. Despite earlier suggestions about friendships extending beyond the basketball court, Eriko expressed concern with not spending enough time with her teammates outside practice and games. She suggested that the apparent harmony of the team was superficial and in her case, largely due to the instructions of the captain rather than being heart felt:

I have behaved according to our captain's instructions without any selfassertion so that I get on with my teammates. I don't know that my teammates have strong friendships or what kind of activities my teammates take part in outside basketball because I always act alone outside basketball (Interview, Eriko).

\section{Satisfaction from effort and self-sacrifice}

In the early stages of this study all the girls said that they were committed to the team but as the study progressed it uncovered some contradictions here as well. Three of the participants always looked forward to practice and to all the competition games but the other three were more concerned with personal relationships than the performance of the team.

Jyuri, Reiko and Eriko looked forward to every practice session and competition game while valuing the importance of the effort and sacrifice required for commitment to study and basketball. They found satisfaction in getting results from the sacrifice required to apply themselves to practice and games when it produced results. Jyuri enjoyed putting in "one hundred percent" at every practice session and every game because she felt it always produced results and was worth it: "I like basketball so I can always endure hard practice without thinking much about how hard it is because good results in the games follow as a result". Satisfaction from having to sacrifice time and effort extended beyond practice sessions and matches for some who suggested that they enjoyed having to commit and make personal sacrifices in terms of their lifestyle for the team. The demands of schooling in Japan and the ways in which it competes with other aspects of adolescents' lives typically leaves little time for leisure (see, Fukuzawa \& LeTendre, 2001).

Reiko said that it was difficult to manage her time with the demands placed on her by schoolwork, commuting between home and school and playing basketball but she felt satisfied with her busy lifestyle, implying she was satisfied because it was busy. Competition for adolescents' time 
and energy between sport and other commitments is a common problem in Western settings (Fraser-Thomas et al., 2008; Weiss and Williams, 2004) but the pleasure and satisfaction that the participants found in dealing with these demands is distinct and suggests the influence of culture and the institutional context.

The girls who were less committed to basketball preferred practice sessions to competition matches and did not seem to be as interested in improving as individuals or as a team. Nor did they take criticism from their coach at all well: "I don't like to be scolded by my coach about my mistakes in the game" (Interview, Junko). For Sachi, Junko and Chika, relationships within the team seemed to be more important than performance on the court, which aligns with the importance placed by girls on relationships in sport suggested in the literature (see, Flintoff \& Scratton, 2003). They made reference to improving in tactics and technique but in general terms about trying harder and putting in a steady effort on everything. This contrasted with the more specific focus of the three players more concerned with team performance such as Jyuri who said that, "I think that I have to practice a lot more to be a good guard player". For Chika in particular, her commitment was to relationships with her teammates more than to her own or the team's performance: "It is an important challenge for me that we understand each other and that I keep a good relationship with my teammates". For her and two other girls, maintaining and developing good relationships was as important as, if not more important than, helping the team get good results and this seems to be where she put in the most effort.

\section{Sense of improvement and learning}

In bukatsudo there is a strong focus on the individual striving to perfect his or her performance in fundamental techniques (Cave, 2004) underpinned by the importance of cultural imperatives such as effort (doryoko) and what Singleton (1993) refers to as gambaru (a verb meaning to persist, do your best). Indeed, Singleton argues that gambaru and shudan ishiki (group consciousness) constitute the hidden curriculum of Japanese institutes of education that contrast with a Western emphasis on IQ and ability. This was evident in this study with the girls taking individual responsibility for self-improvement to contribute to the team effort: "I enjoy playing basketball. My goal for my future is to become a good player who contributes to (the team winning) games so I think that I have to practise skill drill and enhance my basketball skill" (Interview, Sachi).

The girls all spoke about the skills they had learned and the techniques or areas of their game that they felt they needed to work on as individuals to make an appropriate contribution to the team. Four were happy with their rate of improvement, one unsure and one frustrated that she was not improving. For some of the girls these aims of improving 
and contributing to the team's success were driven by goals of achievement in basketball while at school, such as Junko's goal of participating in the high school championship of her prefecture. Being a little more ambitious, Jyuri said that, "I am enjoying basketball and my goal is for my team to win a high school championship in the prefecture".

Four of the girls said that they noticed a considerable improvement in their skill and performance each practice season but Reiko was unsure whether she was improving or not and Eriko did not feel any improvement at all. Chika was happy with how her passing and dribbling were improving and was looking forward to being a shooting guard on the team, which was a goal of hers. Jyuri was also happy with her improvement and the increasing contribution she was able to make to the team effort as a point guard. When these four girls shared their thoughts about their improvement they talked about individual effort and taking on more responsibility but in order to make the best contribution to the team that they could. These four set themselves short term goals that they thought they were achieving but when asked about their long term goals in basketball none of them offered substantial goals related to achievement in basketball and with basketball not featuring in their post schooling lives. Despite this, they enjoyed feeling like they were improving with setting and approaching or achieving short-term goals contributing to them enjoying basketball.

All the girls in the study wanted to enter a prestigious university and had no plans for basketball featuring in their futures beyond being a hobby: "I want to be a journalist who reports on international politics... I think I will be still playing basketball for fun; for a hobby. I see myself with my dream realized" (Interview, Rieko). Others, like Chika, didn't see basketball playing any part of their future at all: "I don't think I will be playing basketball. I will be working for sure". For the girls in this study basketball only featured in their lives beyond school as an occasional activity where they could enjoy practice without getting too serious of not at all..

\section{Discussion}

Studies on participation in youth sport conducted in distinctively different settings provide opportunities for both identifying the ways in which the context shapes the specific nature and meanings of participation in sport and the overlaps and similarities with other settings. Despite the clear influence of the socio-cultural and institutional context on experience in this study we do not see context as a discrete entity at work here. As Dewey (1939: p. 544) argues, the person (organism) and environment (context) cannot be separated because all experience involves an, "interaction of environing conditions and an 
organism". This does not merely mean the surrounding physical conditions but, instead, refers to the person's true environment as that with which $\mathrm{s} /$ he interacts.

In this study the context is not what surrounded the girls in practice and competition. It is what they interacted with to produce particular experiences and suggested learning. For Dewey the true environment is determined by the interaction between the organism and the context (environment) but as one and not as the three separate parts of environment, organism and interaction. Dewey's notion of interaction suggests a deeper sense of integration than merely something done between a separate learner or agent and his/her context. From Dewey's (1938) perspective a learner does not live, have experience and learn in an environment. S/he lives, has experience and learns by means of an environment. This study's identification of how the true environment with which the girls interacted over years of participation in the basketball club shaped their experiences and enjoyment of basketball is made more apparent by its differences from the findings of studies in Western settings.

There is a difference between the nature of peer relations identified in this study and those identified in Western settings but there are also similarities and particularly with the ways in which gender shaped experience. In Western settings peer relationships play an important role in physical activity contexts such as sports clubs and have been linked to establishing a sense of physical competence, moral attitudes and behaviours, and affective outcomes of participation (Smith, 2003). Research also suggests that young people's positive perceptions of peer relationships have a positive effect upon participation in areas such as motivation, enjoyment and perceptions of their competence in the sport that is more marked with girls and women (Ullrich-French \& Smith, 2006; Flintoff \& Scratton, 2003; Weiss \& Smith, 2002).

The way in which having a sense of improvement and growing competence contributed toward positive experiences of being in the team and club in this study also finds common ground with research on youth sport conducted outside Japan (see, Jackobsson, Lundvall \& Redelius, 2014). The importance of feeling competent (Kirk, 2005) and the identification of how effort expended on practice is seen to be worth it when it 'pays off' (see, Lee, Carter \& Xiang, 1995) is also evident in the literature more broadly. The importance of feeling a sense of belonging for wanting to stay in the club and for enjoying it are also typically identified in the literature (see, Jakobsson et al., 2014) but the importance of 'fun' is not evident in this study.

The findings suggest that relationships with teammates and other girls in the club were the most important factor contributing toward enjoyment of being in the club and what made it meaningful for them. This is something that research suggests is valued by adolescent girls in 
sport more broadly (see, Weiss \& Smith, 2002). For three of the six girls interpersonal relationships and the social functioning of the team were more important than its performance. While this suggests that learning of shudan ishiki, was enhanced by being in the basketball club it is seemed to be influenced by the importance adolescent girls place on relationships in a team and on social networks (Chen \& Light, 2006; Flintoff \& Scratton, 2003).

Two of the themes identified in this study support other studies conducted in Western settings by identifying the importance of the social aspects of being in a team and of feeling that they are improving and developing competence. Some of this also overlaps with the gender specific experiences of sport that adolescent girls enjoy but the theme of enjoying being committed to the team, putting in maximum effort and showing persistence and self-sacrifice in other aspects of their lives is culturally distinct. It seems to provide some evidence of how bukatsudo operate to socialize students into the rigours of adult life in Japan and lend support to van Ommen's (2015) suggestion that bukatsudō embody the cultural capital required to find work in Japan - for women and men (van Ommen, 2015).

In Japanese society there has traditionally been an expectation to display effort and persistence in study, sport, work and the range of cultural activities that reproduce dominant culture for males and females (Singleton, 1993). This typically involves work that is testing of will and spirit (seishin), requires enduring tolerance (gaman) and is seen to build spiritual power (see, Rohlen, 1986). Although its influence is now declining it is on display in cultural rituals in Japan such as the gaman taikai (endurance competition) in which individuals demonstrate gaman through acts such as soaking in ice-cold water in winter. In the 1990s Miyamoto (1994, p. 164) suggested that the world of work in Japan that bukatsudō aim to prepare young people for was one in which, "people are expected to suffer at their jobs and turn that into pleasure". While this is not as evident in contemporary Japan it still has a significant influence in the work place.

\section{Conclusion}

The findings of this study support much of the literature on youth sport participation while highlighting the powerful influence of the socio-cultural and institutional context in this particular setting. It suggests the central importance of social interaction, interpersonal relationships and the social nature of being in a team. These are aspects of playing sport that are of particular importance for adolescent girls across a range of socio-cultural and institutional settings in youth sport and which interacted with the culture and institutional setting to shape experience in this study. The powerful effect of a culture-specific, 
institutional setting is most evident in how the participants enjoyed the sense of total commitment to the team and self-sacrifice involved with effort (doryoku) but is also evident in how it shaped positive experiences of the social aspects of being in the club and feeling like they were improving.

\section{References}

Abe, I., Kiyoharam, Y., \& Nakajima, K. (1990). Sport and physical education under fascitization in Japan. The Bulletin of Health and Sport Sciences: University of Tsukuba, 13, 25-46.

Allender, S., Cowburn, G., \& Foster, C. (2006). Understanding participation in sport and physical activity among children and adults: a review of qualitative studies. Health Education Research, 21(6), 826-835.

Auerbach, C. F., \& Silverstein, L. B. (2003). Qualitative data: An introduction to coding and analysis. New York: New York University Press.

Bailey, R., Cope, E., \& Pearce, G. (2013). Why do children take part in, and remain in, sport? A literature review and discussion of implications for sports coaches. International Journal of Coaching Science, 7(1), 56-75.

Broadbent, K. (2003). Women's employment in Japan. London \& New York: Routledge.

Cave, P. (2004). Bukatsudō: The educational role of Japanese school clubs. Journal of Japanese Studies, 30(2), 382-415.

Charmaz, K. (2006). Constructing grounded theory: A practical guide through qualitative analysis. Thousand Oaks, CA: Sage.

Chen, Q., \& Light, R. (2006). 'I thought I'd hate cricket but I love it!': Year six students' responses to Game Sense pedagogy'. Change: Transformations in Education, 9(1), 49-58.

Clarke, A. E., \& Friese, C. (2010). Grounded theorizing using situational analysis. In A Bryant \& K. Charmaz (Eds.), The Sage Handbook of Grounded Theory. London: Sage, pp. 363-397.

Coakley, J., \& White, A. (1992). Making decisions: gender and sport participation among British adolescents. Sociology of Sport Journal, 9, 2035.

Connell, R. W. (1983). Which way is up? Essays on sex, class and Culture. Sydney: Allen \& Unwin.

Côté, J., \& Hay, J. (2002). Children's involvement in sport: a developmental perspective. In J. M. Silver \& D. Stevens (Eds.), Psychological Foundations of Sport. Boston, MA: Allyn and Bacon Publishers, pp. 484-502.

Dewey, J. (1939). Experience, knowledge and value: A rejoinder. In P. A. Schilpp (Ed.), The Philosophy of John Dewey. Evanston, IL.: Northwestern University Press, pp. 515-608.

Doyon, P. (2001). A review of higher education reform in modern Japan. Higher Education, 41(4), 443-470.

Fernandez-Balboa, J-M. (2011). Sailing toward 'Happycity': Ethics plus education. In J. A. Kentel (Ed.), Educating the young: The ethics of care. Bern: Peter Lang, pp. 39-60. 
Flintoff, A., \& Scraton, S. (2003). Stepping into active leisure? Young women's perceptions of active lifestyles and their experiences of school physical education. Sport Education \& Society, 6, 5-21.

Fukuzawa, R. E., \& LeTendre, G. K. (2001). Intense years: How Japanese adolescents balance school, family, and friends (Vol. 50). New York: Routledge.

Fraser-Thomas, J., Côté, J., \& Deakin, J. (2008). Understanding dropout and prolonged engagement in adolescent competitive sport. Psychology of Sport and Exercise, 9, 645-666.

Fry, M. D., \& Gano-Overway, L. A. (2010). Exploring the contribution of the caring climate to the youth sport experience. Journal of Applied Sport Psychology, 22(3), 294-304.

Glaser, B. (1978). Theoretical sensitivity: Advances in the methodology of grounded theory. California: The Sociology Press.

Glaser, B., \& Strauss, A. (1967). The discovery of grounded theory, New York: Aldine.

Herrigel, E. (1971). Zen in the art of archery. New York: Random House, Vintage Books.

Ichiro, H. (2004). The making of a professional football league-the design of the J. League system. In W. Manzenreiter \& J. Horne (Eds.), Football Goes East: Business, Culture and the People's Game in China, Japan and South Korea. New York: Routledge, pp. 38-53.

Ikeda, K. (2010). Ryōsai-kembo, Liberal education and maternal feminism under fascism: Women and sport in modern Japan. The International Journal of the History of Sport, 27(3), 537-552.

Jackobsson, B. T., Lundvall, S., \& Redelius, K. (2014). Reasons to stay in club sport according to Swedish participants: A salutogenic approach'. Sport Science Review, 23(2-3), 205-244.

Keifer, C. W. (1970). The psychological interdependence of family, school, and bureaucracy in Japan. American Anthropologist, 72, 66-75.

Kirk, D. (2005). Physical education, youth sport and lifelong participation: the importance of early learning experiences. European Physical Education Review, 11(3), 239-255.

Kirk, D., \& MacPhail, A. (2003). Social positioning and the construction of a youth sports club. International Review for the Sociology of Sport, 38(1), 2344.

Lee, A., Carter, J. A., \& Xiang, P. (1995). Children's conceptions of ability in physical education. Journal of Teaching in Physical Education, 32(2), 4547.

Lempert, L. B. (2010). Asking questions of the data: Memo writing in the grounded theory tradition. In A. Bryant \& K. Charmaz (Eds), The SAGE handbook of grounded theory. Los Angeles: Sage, pp. 245-264.

Light, R. L. (1999). Regimes of training and the construction of masculinity in Japanese university rugby. International Sports Studies, 2I (2), 39-54.

Light, R. L. (2001). Culture, tactics and embodied masculinity in Japanese and Australian school rugby. International Sports Studies, 23(1/2), 37-46.

Light, R. L. (2006). Situated learning in an Australian surf club. Sport, Education \& Society, 11(2), 155-172.

Light, R. L. (2008). Learning masculinities in a Japanese high school rugby club. Sport, Education and Society, 13(2), 163-180. 
Light, R. L. (2010). Children's social and personal development through sport: A case study of an Australian swimming club. Journal of Sport and Social Issues, 34(4), 266-282.

Light, R. L. (2016). Children, young people and sport: Studies on experience and meaning. Newcastle, UK: Cambridge Scholars Press.

Light, R. L., Harvey, S., \& Memmert, D. (2013). Why children join and stay in sports clubs: Case studies in Australian, French and German swimming clubs. Sport Education and Society, 18(4), 550-566.

Light, R. L., \& Nash, M. (2006). Learning and identity in overlapping communities of practice: Surf club, school and sports clubs. Australian Educational Researcher, 33(1), 145-162.

Light, R. L., \& Yasaki, W. (2003). Breaking the mould: Community, education and the development of professional soccer in Japan. Football Studies, 6(1), 37-50.

MacPhail, A., Gorley T., \& Kirk, D. (2003). Young people's socialisation into sport: a case study of an athletics club. Sport Education \& Society, 8, 251267.

McCarthy, P. J., \& Jones, M. V. (2007). A qualitative study of sport enjoyment in the sampling years. Sport Psychologist, 21(4), 400-416.

McDonald, B. (2004). The university rowing club as a site of moral and social education in Japan. International Sports Studies, 26(2), 15-28.

McDonald, B., \& Komuku, H. (2008). Japanese educational sport and the reproduction of identity. In C. Hallinan \& S. Jackson (Eds.), Sport and Cultural Diversity in a Globalized Word. Oxford: Emerald, pp. 97-110.

Miller, A. (2013). For basketball court and company cubicle: New expectations for university athletes and corporate employees in Japan. Japanese Studies, 33(1), 63-81.

Miyamoto, M. (1994). Straightjacket Society: An Insiders' Irreverent View of Bureaucratic Japan. Tokyo: Kodansha.

OECD Employment outlook (2014). How does Japan compare? Available at: www.oecd.org/japan/EMO-JPN-EN.pdf.

Olds, T., Dollman, J., \& Maher, C. (2009). Adolescent sport in Australia: Who, when, where and what. ACHPER Healthy Lifestyles Journal, 56(1), 11-16.

Passin, H. (1980). Society and Education in Japan. Tokyo: Kodansha.

Richards, L. (2010). Handling Qualitative Data: A Practical Guide (2nd ed.). Los Angeles: Sage.

Roden, D. (1980). Baseball and the quest for national dignity in Meiji Japan. American Historical Review, 85(1), 511-534.

Rohlen, T. (1983). Japanese high schools. Berkley: University of California Press.

Rohlen, T. (1986). Spiritual education in a Japanese bank. In T. Lebra \& W. Lebra (Eds.), Japanese Culture \& Behavior. Honolulu: University of Hawaii Press, pp. 307-338.

Rohlen, T., \& Tendre, G. (1998). Teaching and Learning in Japan. New York: Cambridge University Press.

Sabo, D., \& Veliz, P. (2008). Go out and play: Youth sports in America, East Meadow. New York: Women's Sports Foundation.

Sarrazin, P., Vallerand, R., Guillet, E., Pelletier, L., \& Cury, F. (2002). Motivation and Dropout in Female Handballers: a 21-month prospective study. European Journal of Social Psychology, 32, 395-418. 
Singleton, J. (1993). Gambaru: A Japanese cultural theory of learning. In J. J. Shields (Ed.), Japanese schooling: Patterns of socialization, equality and political control. Pennsylvania: Pennsylvania Sate University Press, pp. 815.

Smith, A. (2003). Peer relationships in physical activity contexts: A road less travelled in youth sport and exercise psychology research. Psychology of Sport and Exercise, 4, 25-39.

Strauss, A., \& Corbin, J. (1990). Basics of Qualitative Research: Grounded Theory Procedures and Techniques. Newbury Park, CA: Sage.

Suzuki, D. T. (1959). Zen and Japanese Culture. Tokyo: Tuttle.

Ullrich-French, S., \& Smith, A. L. (2006). Perceptions of relationships with parents and peers in youth sport: Independent and combined prediction of motivational outcomes. Psychology of Sport and Exercise, 7(2), 193-214.

van Ommen, M. (2015). Extracurricular paths into job markets in contemporary Japan: The way of both pen and soccer Ball. Japanese Studies, 35(1), 85102.

Weiss, M. R., \& Smith, A. L. (2002). Friendship quality in youth sport: Relationship to age, gender, and motivation variables. Journal of Sport \& Exercise Psychology, 24, 420-437.

Weiss, M. R., \& Williams, L. (2004). The why of youth sport involvement: A developmental perspective on motivational processes. In M. R. Weiss (Ed.), Developmental Sport and Exercise Psychology: A Lifespan Perspective. Morgantown, WV: Fitness Information Technology, pp. 223-268.

Williams, L. (1998). Contextual influences and goal perspectives among female youth sport participants. Research Quarterly for Exercise and Sport, 69(1), 47-57.

Wright, J., \& Macdonald, D. (2010). Young people, physical activity and the everyday: the Life Activity project. In J. Wright \& D. Macdonald (Eds.), Young People, Physical Activity and the Everyday. London and New York: Routedge, pp. 1-12.

Yuasa, Y. (1993). The body, self-cultivation, and ki energy. Albany: State University of New York Press. 